\title{
EDITORIAL
}

\section{Chronic cough: a rational approach to investigation and management}

\author{
I.D. Pavord
}

C hronic cough is a common problem: community surveys suggest a prevalence of recurrent cough of up to $40 \%$ and persistent cough of up to $10 \%$ [1-3]. Approximately $10 \%$ of new patients seen in respiratory clinics are referred with an isolated chronic cough [4]. Most patients referred for a specialist opinion are nonsmokers with normal findings on basic screening investigations, such as chest radiograph, serial peak expiratory flow measurements and spirometry. Females account for $60-70 \%$, and many report a long-standing cough, which started at around the time of the menopause [5]. The current evaluation of chronic cough is based on the "anatomic, diagnostic" protocol originally described by IRWIN et al. [6] >20 yrs ago. This investigation protocol is based on the view that most cases of nonasthmatic chronic cough are caused by rhinosinusitus and/or gastrooesophageal reflux $[6,7]$. The investigation protocol remains largely based on expert opinion, and there is a lack of evidence from randomised, double-blind, placebo-controlled trials supporting central tenants of the anatomic, diagnostic protocol $[8,9]$. Nevertheless, there are multiple reports of the successful management of cohorts of patients with chronic cough using variants of the anatomic, diagnostic approach to investigation, and the protocol has largely stood the test of time [10]. Despite this, many clinicians view chronic cough as a difficult clinical problem [11]. Amongst the most significant problems is the difficulty in knowing how far to take investigations in patients who commonly report a long-standing cough, which, although distressing, is not obviously progressive.

The anatomic, diagnostic approach to the investigation of chronic cough has spawned a number of variants varying in their reliance on investigations. These approaches to investigation range from a "test and treat" strategy [12] to empirical treatment trials based on a best guess of the underlying cause of the cough [13]. The former approach often leads to an exhaustive and expensive number of investigations, which, in any one patient, could include: spiromety; peak expiratory flow monitoring; a methacholine inhalation test; induced sputum analysis; endoscopic examination of the upper and lower airways and upper gastrointestinal tract; computerised tomography $(\mathrm{CT})$ of the thorax and sinuses; and oesophageal manometry and $\mathrm{pH}$ monitoring. Abnormalities of some of these tests are common in patients with airway disease of any kind [13-16]; other tests, such as bronchoscopy and chest CT

CORRESPONDENCE: I.D. Pavord, Dept of Respiratory Medicine and Thoracic Surgery, Glenfield Hospital, Groby Road, Leicester LE3 9QP, UK. Fax: 44 1162367768. E-mail: ian.pavord@uhltr.nhs.uk scanning, have a very low yield in the absence of suggestive symptoms or chest radiographic changes [12, 13, 17]. Furthermore, with the exception of sputum eosinophilia and a positive response to corticosteroid treatment [4, 18], there is limited evidence that abnormalities detected by these investigations are predictive of the success of a treatment $[9,19]$.

Recognising the limitations of the test and treat approach to investigation of chronic cough, KASTELIK et al. [13] have reported a probability-based algorithm for the investigation and management of chronic cough in this issue of the European Respiratory Journal. The investigation algorithm is similar to that recently recommended by the ERS Task Force on the diagnosis and management of chronic cough [20], and the results go some way towards validating this approach. Important elements of the algorithm include a careful clinical assessment, and targeted investigations and treatment trials based on clinical suspicion. The results were impressive: $93 \%$ of patients reported substantial improvement or complete resolution of their cough; $26 \%$ were managed without recourse to special investigation; and there was a strong suspicion that treatment success was achieved more rapidly, and at a lower cost, than it would have been with other cough investigation algorithms.

Another notable feature of the study by KASTELIK et al. [13] was that the presence of regular sputum production and chest radiograph abnormalities were both predictive of an intrapulmonary pathology. Bronchiectasis, which was largely diagnosed after a chest CT scan, was a common diagnosis. Earlier case series have not reported such a high incidence of bronchiectasis [6,7], perhaps because high-resolution thoracic CT scanning was not an established part of the investigation algorithm. The series reported by KASTELIK et al. [13] also differs from earlier studies in that only $52 \%$ of patients were thought to have what had hitherto been thought to be the most common causes of isolated chronic cough: asthma, rhinitis and gastro-oesophageal reflux. Other recent case series have come to a similar conclusion $[4,19]$. One potential explanation is the overdiagnosis of rhinitis in earlier studies, perhaps because a response to nonselective antihistamines was wrongly assumed to reflect a specific effect on rhinitis-associated cough when, in fact, it was due to the broad antitussive effect of these agents $[21,22]$. The difference could also reflect different referral practices. Many series have not included patients with chest radiograph abnormalities, and the prevalence of cough-variant asthma, eosinophilic bronchitis, rhinitis-associated cough and gastro-oesophageal-associated cough is likely to depend on the extent to which treatment trials are instigated before referral. 
Whatever the explanation, the clear implication of these studies is that there is now more to isolated chronic cough than asthma, rhinitis and gastro-oesophageal reflux.

The prospect for identifying a treatable cause of chronic cough was poor in patients who had no symptoms suggesting a pulmonary or extrapulmonary cause for their cough, and had normal investigations, with only a third reporting improvement in response to empirical treatment trials. There is increasing recognition amongst clinicians with an interest in cough that an important minority of patients have no obvious cause for their cough [4, 19, 23, 24]. Recent research has identified some potential explanations for otherwise unexplained chronic cough. A case control study has highlighted an association with organ-specific autoimmune disease, particularly thyroid disease [23], and there is evidence of a low-grade lymphocytic airway and alveolar inflammation [5, 24], with an abnormal release of protussive mediators in the airway [25], in some patients with unexplained chronic cough. Familial chronic cough has been described in a family with hereditary sensory neuropathy type 1 [26], and cough has also been linked to Holmes-Adie syndrome with autonomic dysfunction [27], suggesting a wider association with neurological diseases. Chronic enlargement of the tonsils [28] and external or middle ear disease [20] are other potential causes of otherwise unexplained cough; they are important conditions to consider, since the cough is treatable.

The many clinicians who find isolated chronic cough difficult will view the investigation algorithm proposed by KASTELIK et al. [13] as a rational and feasible approach to the investigation of a common clinical problem. One result of its widespread adoption might be an increase in the proportion of patients with unexplained chronic cough seen in clinics that provide a specialist cough service. Clinicians providing such a service will need to be aware of less common causes; they may find that they need to develop a more intensive approach to assessment, which incorporates objective markers of cough severity to validate the presence of cough and assess its response to treatment.

\section{REFERENCES}

1 Cullinan P. Persistent cough and sputum: prevalence and clinical characteristics in south east England. Respir Med 1992; 86: 143-149.

2 Janson C, Chinn S, Jarvis D, Burney P. Determinants of cough in young adults participating in the European Community Respiratory Health Survey. Eur Respir J 2001; 18: 647-654.

3 Di Pede C, Viegi G, Quackenboss JJ, Boyer-Pfersdorf P, Lebowitz MD. Respiratory symptoms and risk factors in an Arizona population sample of Anglo and MexicanAmerican whites. Chest 1991; 99: 916-922.

4 Brightling CE, Ward R, Goh KL, Wardlaw AJ, Pavord ID. Eosinophilic bronchitis is an important cause of chronic cough. Am J Respir Crit Care Med 1999; 160: 406-410.

5 Birring SS, Brightling CE, Symon FA, Barlow SG, Wardlaw AJ, Pavord ID. Idiopathic chronic cough: association with organ specific autoimmune disease and bronchoalveolar lymphocytosis. Thorax 2003; 58: 1066-1070.
6 Irwin RS, Corrao WM, Pratter MR. Chronic persistent cough in the adult: the spectrum and frequency of causes and successful outcome of specific therapy. Am Rev Respir Dis 1981; 123: 413-417.

7 Irwin RS, Curley FJ, French CL. Chronic cough. The spectrum and frequency of causes, key components of the diagnostic evaluation, and outcome of specific therapy. Am Rev Respir Dis 1990; 141: 640-647.

8 Kiljander TO, Salomaa ERM, Hietanen EK, Terho EO. Chronic cough and gastro-oesophageal reflux: a doubleblind placebo-contolled study with omeprazole. Eur Respir J 2000; 16: 633-638.

9 Ours TM, Kavuru MS, Schilz RJ, Richter JE. A prospective evaluation of esophageal testing and a double-blind, randomised study of omeprazole in diagnostic and therapeutic algorithm for chronic cough. Am J Gastroenterol 1999; 94: 3131-3138.

10 Irwin RS, Madison JM. The diagnosis and treatment of cough. N Engl J Med 2000; 343: 1715-1721.

11 Morice AH. Chronic cough: not such a heartsink. Thorax 2003; 58: 829.

12 Palombini BC, Villanova CA, Araujo E, et al. A pathogenic triad in chronic cough: asthma, postnasal drip syndrome and gastrooesophageal reflux disease. Chest 1999; 116: 279-284.

13 Kastelik JA, Aziz I, Ojoo JC, Thompson RH, Redington AE, Morice AH. Investigation and management of chronic cough using a probability-based algorithm. Eur Respir J 2005; 25: 235-243.

14 Britton JR. Airway hyperresponsiveness and the clinical diagnosis of asthma: histamine or history? J Allergy Clin Immunol 1992; 89: 19-22.

15 Hunter CJ, Brightling CE, Woltmann G, Wardlaw AJ, Pavord ID. A comparison of the validity of different diagnostic tests in adults with asthma. Chest 2002; 121: 1051-1057.

16 Sontag S, O'Connell S, Khandelwal S, et al. Most asthmatics have gastrooesophageal reflux with or without bronchodilator therapy. Alimentary Tract 1990; 99: 613-620.

17 Irwin RS, Boulet LP, Cloutier MM, et al. Managing cough as a defence mechanism and as a symptom. A consensus panel report of the American College of Chest Physicians. Chest 1998; 114: 133S-181S.

18 Brightling CE, Ward R, Wardlaw AJ, Pavord ID. Airway inflammation, airway responsiveness and cough before and after inhaled budesonide in patients with eosinophilic bronchitis. Eur Respir J 2000; 15: 682-686.

19 McGarvey LPA, Heaney LG, Lawson JT, et al. Evaluation and outcome of patients with chronic non-productive cough using a comprehensive diagnostic protocol. Thorax 1998; 53: 738-743.

20 Morice AH, Fontana GA, Sovijarvi AR, et al. The diagnosis and management of chronic cough. Eur Respir J 2004; 24: 481-492.

21 McLeod RL, Mingo G, O’Reilly S, Ruck LA, Bolser DC, Hey JA. Antitussive action of antihistamines is independent of sedative and ventilation activity in the guinea pig. Pharmacology 1998; 57: 57-64.

22 Rafferty P, Jackson L, Smith R, Holgate ST. Terfenadine, a potent histamine H1-receptor antagonist in the treatment 
of grass pollen sensitive asthma. Br J Clin Pharmacol 1990; 30: 229-235.

23 Birring SS, Murphy AC, Scullion JE, Brightling CE, Browning M, Pavord ID. Idiopathic chronic cough and organ specific autoimmune diseases: a case control study. Respir Med 2004; 98: 242-246.

24 Lee SY, Cho JY, Shim JJ, et al. Airway inflammation as an assessment of chronic nonproductive cough. Chest 2001; 120: 1114-1120.

25 Birring SS, Parker D, Brightling CE, Bradding $\mathrm{P}$, Wardlaw AJ, Pavord ID. Induced sputum inflammatory mediator concentrations in chronic cough. Am J Respir Crit Care Med 2004; 169: 15-19.
26 Kok C, Kennerson ML, Spring PJ, Ing AJ, Pollard JD, Nicholson GA. A locus for hereditary sensory neuropathy with cough and gastroesophageal reflux on chromosome 3p22-p24. Am J Hum Genet 2003; 73: 632637.

27 Kimber J, Mitchell D, Mathias CJ. Chronic cough in the Holmes-Adie syndrome: association in five cases with autonomic dysfunction. J Neurol Neurosurg Psychiatry 1998; 65: 583-586.

28 Birring SS, Passant C, Patel RB, Prudon B, Murty GE, Pavord ID. Chronic tonsillar enlargement and cough: preliminary evidence of a novel and treatable cause of chronic cough. Eur Respir J 2004; 23: 199-201. 